\title{
La vigilancia de la recta administración de justicia por el Tribunal de la Signatura Apostólica. Comentario a algunos decretos recientes en materia disciplinar
}

Francisca PÉREZ-MADRID

Profesora Titular de Derecho Eclesiástico del Estado

Universidad de Barcelona. Facultad de Derecho

orcid 0000-0002-3695-3773

fperezmadrid@gmail.com

SumARIO: 1. La vigilancia de la actividad judicial por parte de la Signatura Apostólica. 2. La imposición de una multa y remoción del oficio al Vicario Judicial y al Defensor del vínculo (Decreto Prot. N. 48706/14 VT). 2.1. Decreto del Tribunal de la Signatura Apostólica contra el Vicario fudicial, Rdo. Z. 2.2. Decreto del Tribunal de la Signatura Apostólica dirigido contra el Defensor del vínculo $R d o$. S. 3. La remoción del oficio de Vicario Judicial por la pérdida de la íntegra fama (Decreto Prot. N. 48191/13 VT). 3.1. Recurso jerárquico ante el Tribunal de la Signatura Apostólica por la remoción de oficio de un Vicario judicial. 3.2. Petición de revocación del Decreto al Prefecto del Tribunal de la Signatura Apostólica. 4. Una visita canónica a un Tribunal interdiocesano ordenada por el Tribunal de la Signatura Apostólica (Decreto 43162/09 VT).

\section{La Vigilancia de la Actividad Judicial POR PARTE DE LA SigNATURA APOSTÓLICA}

L 1 Código de 1983 reduce a un único canon, el c. 1445, el tratamiento legislativo específico del Tribunal de la Signatura Apostólica. Sin hacer distinción de Secciones, de los distintos apartados del canon se advierte el mantenimiento del triple aspecto de atribución de competencias: la judicial 
propiamente dicha, la contencioso-administrativa y la administrativa. En el c. $1445, \S 3$ se dice que corresponde al Tribunal de la Signatura «vigilar sobre la recta administración de la justicia y determinar que se proceda contra los abogados o procuradores, si es necesario». Se trata del ejercicio de una potestad administrativa sobre todos los tribunales eclesiásticos esparcidos por el mundo, a excepción de la Rota Romana.

$\mathrm{El}$ inciso «si es necesario» del canon mencionado subraya el carácter subsidiario de la Signatura en este ámbito; será el Moderador de cada Tribunal quien deberá intervenir en primer lugar. Así se ha recogido en el art. 111, 2 de la Instrucción Dignitas connubii donde se establece que el Moderador o el grupo de Obispos deberán proveer cuando haya impericia, pérdida de buena fama, negligencia o abuso por parte de los patronos y procuradores, adoptando las medidas adecuadas, sin excluir -se entiende, posteriormente-, la prohibición de ejercer en el tribunal ${ }^{1}$.

En 1988, el art. 124, 1 de la Const. Apost. Pastor bonus utilizó una fórmula idéntica al Código de Derecho Canónico para definir la mencionada responsabilidad de vigilancia. En su momento, destacó De Diego-Lora que la Pastor bonus no añadía novedades a la regulación anterior. Concretamente, echaba en falta que no se hubiera hecho una «referencia más general a todos los que actúan en el Tribunal de la Signatura en los diversos oficios del mismo, en cuyo caso el precepto no resultaría peyorativo para los Patronos de causas, que por otra parte ya cuentan con propios preceptos disciplinarios en los cc. 1487-1489, que al mismo tiempo señalan la autoridad competente que ha de adoptar esas medidas sancionadoras administrativas» ${ }^{2}$. Igualmente, el

${ }^{1}$ Dice la Dignitas connubii en el art. 111. «1. Los abogados y procuradores que cometan delitos contra el encargo a ellos encomendado, deben ser castigados conforme a derecho (cfr. cc. 1386; 1389; 1391$, n. $2 ; 1470,2 ; 1488-1489)$. 2. Si resulta que los mismos no están a la altura de su oficio por impericia, pérdida de la buena fama, negligencia o abuso, el Obispo Moderador del tribunal o el grupo de Obispos deben proveer adoptando las medidas adecuadas, sin excluir, si el caso lo requiere, la prohibición de ejercer el patrocinio en su tribunal».

2 Además, sostenía que «dicha actividad administrativa de vigilancia debería quedar bien diferenciada y ser atribuida en especial a determinados miembros del Supremo Tribunal, que se constituirían como órgano administrativo a estos efectos, sometida su actividad a normas propias del procedimiento administrativo. Si como Tribunal de justicia, al juzgar acerca de la legalidad de las actuaciones de otros tribunales de la Iglesia, advirtiera irregularidades en las conductas de los que actuaron con oficio eclesiástico o como Patronos de parte en las causas, el Tribunal de justicia no deberá emitir juicio sobre dichas irregularidades, sino que sería deseable que las ponga en conocimiento del órgano administrativo, constituido a dicho fin en el seno del propio Tribunal, para que obre en consecuencia». Cfr. C. DE DIEGo Lora, Vigilancia y control de legalidad de los Tribunales Eclesiásticos por el Tribunal Supremo de la Signatura Apostólica, Ius Canonicum 59 (1990) 133- 
Motu Proprio Iusti iudicis de 1988, únicamente preveía sanciones para los abogados y procuradores.

Años más tarde, en 2008, la Lex propria (en adelante, LP) del Tribunal de la Signatura Apostólica incorporó un cambio interesante en cuanto a los sujetos destinatarios de tal control ${ }^{3}$. Concretamente el art. 35 de la LP dice: «Corresponde también a la Signatura Apostólica la vigilancia de la recta administración de justicia, y en especial: 1) determinar que se proceda contra los ministros de los tribunales, los abogados o los procuradores, si es necesario» ${ }^{4}$. Por tanto, ya no son sólo los abogados y procuradores quienes están sujetos a control, sino todos aquellos que participen en la administración de la justicia eclesiástica ${ }^{5}$. Es una lógica consecuencia del séptimo principio directivo para la reforma del CIC de 1917, cuando indicaba la necesidad de «proclamar que el principio de tutela jurídica se aplica por igual en derecho canónico a los superiores y a los súbditos, de tal manera que se desvanezca cualquier sospecha de arbitrariedad en la administración eclesiástica».

149. Ver también A. López Medina, La confirmación obligatoria de sentencias declarativas de nulidad matrimonial. Cuestiones debatidas en la Comisión para la reforma del Código de Derecho Canónico [19771981], The Person and the Challenges 5 (2015) 217.

${ }^{3}$ En adelante se citará la Lex propria como LP. Cfr. las Normae speciales del 1968, art. 17, 2, 6. Las Normae speciales aprobadas ad experimentum el día 23 de marzo del año 1968 estuvieron en vigor durante cuarenta años, en un periodo de profunda revisión de la legislación canónica. Juan Pablo II promulgó el 25 de enero de 1983 el Codex Iuris Canonici; el 28 de junio de 1988 fue aprobada la Constitución Apostólica Pastor bonus; faltaba entonces afrontar la redacción de una Ley propria que, conforme al artículo 125 de la Constitución Apostólica Pastor bonus, rigiera el Tribunal Supremo de la Signatura Apostólica. Ésta fue finalmente aprobada por Benedicto XVI en el Motu Proprio «Antiqua Ordinatione» en 2008.

${ }^{4}$ El subrayado es mío. Ver también el art. 75 de la Instrucción Dignitas connubii, en su apartado 2, cuando afirma: «Cuando la recta administración de la justicia (por parte de los jueces o de otros adjuntos y colaboradores del tribunal) se vea impedida por negligencia, impericia o abusos, el Obispo Moderador del tribunal o el grupo de Obispos deben proveer adoptando las medidas oportunas, sin excluir, si el caso lo requiere, la remoción del oficio».

${ }^{5}$ El CIC establece en el c. 1457 que «los jueces que rehúsen administrar justicia aun siendo cierta y evidentemente competentes, o que se declaren competentes sin ningún título jurídico que legitime esa competencia, y conozcan y decidan las causas, o violen la ley del secreto, o por dolo o negligencia grave causen otro daño a las partes, pueden ser castigados con penas adecuadas por la autoridad competente, incluso con la privación del oficio». A mi juicio se refiere a sanciones penales, no administrativas. Se dice en la norma citada que estos supuestos podrán ser castigados con penas adecuadas, pero no parece que resulte proporcional -adecuado- pensar en sanciones penales propiamente dichas para estos casos, que, además, están tipificados sistemáticamente fuera del Libro dedicado a la materia penal. Por otro lado, el supuesto de hecho, la infracción, según el criterio cuantitativo que puede tenerse en cuenta para delimitar la antijuridicidad administrativa de la pena, responde más a un supuesto de ilicitud administriva disciplinar. No puede decirse que los supuestos de hecho recogidos en el canon citado posean una antijuridicidad con relevancia de delito, sino más bien de contravención. 
Los actos ilícitos previstos por el CIC 83 y reiterados por la Dignitas connubii, que pueden ser sancionados en un procedimiento disciplinar pueden obtenerse a partir de diversas fuentes; así los cc. 1389, 1457, 1, 1453 a 1456, 1483, 1488, 1489, 1604; arts. 33, 35, 2, 36, 110 de la Dignitas connubii; y el Motu Proprio Iusti iudicis, arts. 4 y 6.

Los arts. 106 a 109 LP concretan cómo se ha de proceder en los supuestos a los que se refiere el art. $35 \mathrm{LP}^{6}$. En primer lugar, se establece que es competencia del Prefecto decidir sobre esos asuntos, con el voto previo del Promotor de justicia, oído el Secretario de la Signatura; si fuera procedente, se habrá de oír además al Defensor del vínculo. El Congreso tratará acerca de los asuntos más importantes ${ }^{7}$.

El Secretario, contando previamente con el voto del Promotor de justicia, podrá rechazar de entrada un recurso o petición cuando conste un manifiesto defecto de presupuesto o de fundamento, aunque siempre quedará firme la facultad de recurrir conforme al art. $28,1 \mathrm{LP}^{8}$.

Resulta lógico que para poder realizar de forma efectiva cierta vigilancia sea preciso contar con algún sistema para recabar información sobre el estado y la actividad de los Tribunales. De ahí que cada año en enero los Tribunales, sean diocesanos, interdiocesanos, de la Iglesia latina o de la Iglesia oriental, deberán elaborar un informe firmado por el Vicario judicial según el modelo

${ }^{6}$ Sobre la Lex propria, F. DANEels, La nuova Lex propria del Supremo Tribunale della Segnatura Apostolica, L'Osservatore Romano, 24-XII-2008, 7; E. LABANDEIRA, Tratado de derecho administrativo canónico, Pamplona 1993; J. Miras - J. CANOSA - E. BAuRA, Compendio de derecho administrativo canónico, Pamplona 2005; A. VALLINI, Dalle «Normae speciales» alla «Lex propria»: itinerario di una riforma, en P. A. BonNet - C. Gullo (eds.), La Lex propria del S. T. della Segnatura Apostolica, Città del Vaticano 2010, 62; Motu proprio «Antiqua ordinazione» di promulgazione della Lex propria del Supremo Tribunale della Segnatura Apostolica, del 21-VI-2008 (con nota de J. LlobelL, La nuova «Lex propria» della Segnatura Apostolica e i principi del processo canonico), Ius Ecclesiae 21 (2010) 441-478. Una traducción al castellano del Motu Proprio «Antiqua Ordinatione», por el que se promulga la Ley propria del Tribunal Supremo de la Signatura Apostólica, preparada por el Dr. Pablo Mones y revisada por el Prof. Jorge Miras se encuentra publicada en Ius Canonicum 53 (2013) 227-262.

${ }^{7}$ La composición del llamado Congreso es la siguiente (art. 22, 1 LP): el Prefecto, el Secretario, el Promotor de justicia, el Defensor del vínculo y, si concurrieran, los Promotores de justicia sustitutos así como otros que puedan haber sido designados en las causas para el oficio de promotor de justicia o Defensor del vínculo con la asistencia del Prepósito de la Cancillería; también pueden ser invitados, a juicio del Prefecto, los Referendarios cuya presencia se considere útil. Cabe que se abstenga o inhiba algún juez si procede conforme a derecho (cc. 1448, 1 CIC y 1106, 1 CCEO).

8 Art. 28. 1. «A no ser que se disponga otra cosa, contra un decreto no meramente ordenatorio del Secretario cabe recurso motivado al Prefecto, que se ha de interponer en el plazo perentorio de diez días». 
que facilita la Signatura Apostólica ; se deberán agregar además diversas observaciones del Vicario judicial ${ }^{10}$.

Los arts. 110-112 LP, describen cómo se ha de proceder tras la presentación de dichos informes anuales. En principio es el Secretario quien envía los oportunos comentarios u observaciones a los interesados tras leer el informe correspondiente (art. 110, 1 LP).

Cuando haya una denuncia contra algún tribunal, el Secretario, oído el Obispo Moderador según lo requiera el caso, el Vicario judicial o el juez de la causa, y con el voto previo del Promotor de justicia, decidirá si se debe proceder y de qué modo, quedando a salvo la competencia de los tribunales y de los jueces. Cuando sea necesario hacer observaciones sobre cuestiones más graves, se habrá de remitir el asunto al Prefecto.

En el caso de que se detecten irregularidades graves, establece el art. 111 LP que será el Congreso quien decida sobre los preceptos que se habrá de dar al tribunal para velar por la recta jurisprudencia, o para que, en adelante, cumpla el modo de proceder prescrito por el derecho, así como sobre el traslado de una causa a otro tribunal, la suspensión de la ejecución de una decisión dictada, y sobre la inspección del tribunal.

$\mathrm{El}$ artículo clave acerca de estas causas disciplinares es el art. $113^{11}$. Si se deben hacer observaciones acerca del personal de algún tribunal, abogados o

9 Benedicto XVI explicaba en un discurso a la Plenaria de la Signatura Apostólica: «La función de este Tribunal, de hecho, no se limita al ejercicio supremo de la función judicial, sino que también lleva a cabo como oficio propio, en el ámbito ejecutivo, la supervisión de la recta administración de la justicia en el Corpus Ecclesiae (cfr. Const. Apost. Pastor bonus, art. 121; Lex propria, art. 32). Esto implica, entre otras cosas, como la Lex propria indica, la recogida actualizada de información sobre el estado y la actividad de los tribunales locales a través del informe anual que cada tribunal tiene que enviar a la Signatura apostólica; la organización y elaboración de los datos que vienen de ellos; la identificación de estrategias para la valoración de los recursos humanos e institucionales en los tribunales locales, así como el ejercicio constante de la función de orientación dirigida a los moderadores de los tribunales diocesanos e interdiocesanos, a los que compete institucionalmente la responsabilidad directa de la administración de la justicia», BENEDICTO XVI, A los participantes en la plenaria del Tribunal Supremo de la Signatura Apostólica, Sala del consistorio, viernes 4 de febrero de 2011.

10 Éstas podrán tratar sobre: 1) las investigaciones previas o sea pastorales de las cuales en los arts. 2-5 de la Ratio procedendi unida a las dos mencionadas Cartas Apostólicas; 2) las secciones instructorias y su organización; 3) los cambios que, tal vez, hayan sido introducidos en la organización del Tribunal; 4) las normas emanadas y observadas acerca de los gastos procesales, los honorarios de los abogados y el gratuito patrocinio. 5) la formación de los ministros del tribunal, las iniciativas locales para su formación permanente y los títulos académicos que deben conseguir; 6) asuntos notables encontrados en materia judicial ante el Tribunal.

11 Mientras que las Normas especiales de 1968 contemplaban esta actividad dentro de la función judicial, los desarrollos normativos posteriores la han considerado administrativa (c. $1455,3,1^{\circ} \mathrm{y}$ art. 124, 1 Pastor bonus). 
procuradores, el Prefecto normalmente manda al Moderador del Tribunal que examine la cuestión ${ }^{12}$, provea si es necesario como se comentaba en párrafos anteriores ${ }^{13}$, y a continuación informe; no obstante, la decisión del Moderador puede ser revocada o corregida, incluso de oficio, en el Congreso (art. 113, 1 LP).

Si se plantea una acción disciplinar ante la Signatura, el Promotor de justicia es quien deberá preparar el escrito de demanda y, tras sopesar los argumentos de la defensa, lo confirmará o lo enmendará; posteriormente, tras haber dado la posibilidad de responder, se decidirá sobre el asunto en el Congreso (art. 113, 2 LP). En cualquier caso, el Prefecto podrá imponer una amonestación fuera del Congreso.

Es lógico que la Signatura Apostólica deba intervenir cuando verifique que es necesario, a partir de recursos o denuncias interpuestas; pero también, podrá actuar ex officio, cuando sea preciso.

No obstante, es importante insistir, la actividad de la Signatura no disminuye la función de vigilancia que tiene cada Obispo diocesano sobre su tribunal o bien del Obispo designado sobre el tribunal interdiocesano ${ }^{14}$. Juan $\mathrm{Pa}$ blo II en un discurso a la Rota Romana del 29 de enero de 2005 recordaba: «Los Obispos [...] son por derecho divino los jueces de sus comunidades. Y en nombre de ellos los tribunales administran la justicia. Ellos están, por tanto, llamados a comprometerse personalmente para garantizar la idoneidad de los miembros de los tribunales diocesanos o interdiocesanos, de los cuales ellos son los Moderadores, y para verificar la conformidad de las sentencias con la doctrina recta. Los sagrados Pastores no pueden pensar que el trabajo de sus tribunales es una cuestión meramente "técnica", de la que pueden desinteresarse, confiándola enteramente a sus vicarios judiciales».

Así, los Reglamentos de los Tribunales eclesiásticos de las diócesis suelan contener preceptos relativos a posibles medidas disciplinarias. En la mayor parte de los casos, dichas normas establecen la inhabilitación o la exclusión del

12 Éste deberá seguir al menos lo previsto en el c. 50.

13 Así lo establece el art. 75 de la Instrucción Dignitas connubii, en su apartado 2, cuando afirma: «Cuando la recta administración de la justicia (por parte de los jueces o de otros adjuntos y colaboradores del tribunal) se vea impedida por negligencia, impericia o abusos, el Obispo Moderador del tribunal o el grupo de Obispos deben proveer adoptando las medidas oportunas, sin excluir, si el caso lo requiere, la remoción del oficio».

${ }^{14}$ Sobre el papel del Obispo como juez, vid. R. BERTOLINO, La tutela dei diritti nella comunitá ecclesiali, Ius Canonicum 46 (1983) 547-577. 
elenco, en el caso de los abogados, para poder ejercer en el Tribunal cuando se haya cometido una infracción muy grave ${ }^{15}$.

A continuación, realizaré el comentario de cinco Decretos de la Signatura Apostólica relacionados con el ejercicio del deber de vigilancia de la Administración de Justicia. En todos se sanciona a los miembros de los Tribunales eclesiásticos -el Vicario judicial, el Defensor del vínculo, y también en un caso, al notario- a causa de las infracciones que han cometido en el ejercicio de sus funciones ${ }^{16}$. En alguno de los supuestos, como veremos a continuación, se imponen sanciones administrativas graves ${ }^{17}$.

15 Vid. el Reglamento del Tribunal eclesiástico metropolitano de Madrid de 2001. En el art. 42 se prevé como ilícito el retraso injustificado de las causas por parte de los Jueces, Ministros, y Ayudantes del Tribunal o bien el actuar con negligencia o mala fe en el cumplimiento de sus deberes o sin el debido respeto a las personas, incumpliendo leyes generales y/o particulares. Los arts. 43, 44 y 45 se refieren a letrados y procuradores. $\mathrm{El}$ art. 46 incorpora una cláusula en blanco -a mi juicio, discutible-, por la que se permite sancionar cualquier otra conducta que contradiga las normas generales o particulares que regulan el proceso, aunque no estén previstas en los artículos precedentes. Muy similar el Reglamento de la diócesis de Osma-Soria. En su art. 17, 3 establece en términos muy amplios que «a los jueces y demás colaboradores del Tribunal que cometan un acto ilícito contra el encargo que se les ha confiado, se deben aplicar las sanciones previstas por la ley» (cfr. DC, art. $75, \$ 1$ ). El artículo 30 dispone también: «Los jueces, ministros, y ayudantes del Tribunal que retrasasen injustificadamente la tramitación de las causas, o actuasen con negligencia o mala fe en el cumplimiento de sus deberes o sin el debido respeto a las personas, o incumpliesen las leyes generales y/o particulares, especialmente lo dispuesto en los cc. 1455, 1456 y 1457, serán sancionados, según la gravedad, con apercibimiento, amonestación, suspensión temporal o privación del oficio». Igualmente, el de Coria-Cáceres, en el que se dice que «el régimen disciplinario se regirá por las mismas reglas establecidas con carácter general para el desempeño de dichas profesiones en los Juzgados y Tribunales de España» (art. 25). En el de Valencia, se establece en el art. 58, 2 que cuando los honorarios sean excesivos, según los límites fijados anualmente por decreto, se podrá determinar la inhabilitación temporal o definitiva para intervenir en el foro eclesiástico. Sobre los aspectos económicos, hace algunas referencias de interés, D. M. GÓMEZ ARCE, Normas de los tribunales eclesiásticos españoles: aspectos económicos, REDC 62 (2005) 501-585.

${ }^{16}$ Sobre la reclamación reiterada de la doctrina para que se publiquen las resoluciones del Tribunal de la Signatura de forma sistemática, vid. S. BerLINGò, La competenza di legittimità e di merito della Segnatura Apostolica secondo la Lex propria, Stato, Chiese e pluralismo confessionale. Rivista telematica (www.statoechiese.it), aprile 2009, 21-23; J. CANOSA, La funzione della giurisprudenza della Segnatura Apostolica nello sviluppo del diritto amministrativo canonico, Ius Ecclessiae 17 (2005) 414-415; E. BAURA, El desarrollo normativo posterior a la Constitución Apostólica Pastor bonus de los tribunales de la Curia Romana, Ius Canonicum 58 (2018) 28-31.

17 Todos los decretos fueron decididos por el Prefecto, tras considerar los respectivos asuntos en el Congreso aunque el art. 113, 3 LP prevé que el Prefecto pueda «amonestar» fuera del Congreso, probablemente porque dicha advertencia no cambia la posición legal del sujeto. En cualquier caso, esta facultad de sancionar sin consultar con nadie debe ejercerse con precaución, porque la «monitio» en el Derecho canónico tiene indudables consecuencias (ver cc. 1339 y 1347, $\$ 1$, además del posible impacto que pueda tener en el momento de la renovación de su función, ante una posible promoción, en la fama, etc.); concretamente el art. 70 del RGCR lo incluye entre las sanciones. 


\section{LA IMPOSICIÓN DE UNA MULTA Y REMOCIÓN DEL OFICIO AL VICARIO} JUDiCIAL Y AL DEFENSOR DEL VINCULO (DECRETO PROT. N. 48706/14 VT)

Con la misma referencia y fecha, tenemos dos decretos referentes a los mismos hechos; el primero se dirige y sanciona al Vicario Judicial (Decreto 2.1), y el segundo se dirige al Defensor del vínculo del mismo Tribunal (Decreto 2.2).

\subsection{Decreto contra el Vicario fudicial, Rdo. Z}

Prot. N. 48706/14 VT

Disciplinaris

(Rev.mus Z)

Edito die 16 ianuarii 2013 decreto rotali, quo sententia primi gradus, die 30 novembris 2011 a Foro $\mathrm{C}$ pro nullitate matrimonii $\mathrm{A} / \mathrm{T}$ lata, ob ius defensionis denegatum nulla declarata est, die 11 octobris 2013 Cl.mus T, pars conventa, ab Exc.mo Episcopo C summam 13.721,35 dollariorum americanorum petiit, ut indemnis ipse fieret $\mathrm{ab}$ emolumento Cl.mo Y soluto pro patrocinio in primo iudicii gradu, «because - inquit - of procedural irregularities by the Tribunal Judge, my advocate was required to file numerous pleadings in defense of my interests». Decretum enim rotale de actis valide parti conventae non publicatis necnon de attestationibus sub secreto positis cavet.

A Rev.mo Vicario iudiciali $Z$ atque iudice unico in causa de qua nomine Exc.mi Episcopi C expensarum restitutione denegata atque ab Exc.mo ipso Episcopo denegatione confirmata, Cl.mus T ad H.S.T. die 25 novembris 2013 provocavit.

Rev.mus Promotor Iustitiae, causa disciplinari apud H.S.T. instituta, libellum causae introductorium porrexit, quem Exc.mus Secretarius una cum citatione ad Rev.mum $\mathrm{Z}$ misit.
Prot. N. 48706/14 VT

De disciplina

(Rmo. Z)

Una vez emanado el decreto rotal de 16 de enero de 2013 mediante el cual la sentencia de primera instancia pro nullitate del matrimonio $\mathrm{A} / \mathrm{T}$, dada por el Tribunal C el día 30 de noviembre de 2011, es declarada nula; el día 11 de octubre, la parte demandada $\mathrm{T}$, pidió al Obispo C la suma de 13.721,35 dólares americanos para indemnizarle por el emolumento pagado a $\mathrm{Y}$ en concepto de patrocinio por la causa en primer grado de juicio, «ya que -dice- a causa de las irregularidades procesales por parte del Juez del Tribunal, mi abogado tuvo que presentar numerosos alegatos en defensa de mis intereses». En efecto, el decreto rotal evidencia las actas no publicadas válidamente a la parte demandada, así como las declaraciones testificales puestas bajo secreto.

El Sr. T recurrió ante este Supremo Tribunal el 25 de noviembre de 2013 por la denegación de restitución de los gastos, realizada por el Vicario judicial $Z$ y juez único, en nombre del Obispo $\mathrm{C}$ (y confirmada por parte de éste).

El Rmo. Promotor de Justicia, una vez iniciada la causa disciplinar ante la Signatura, presentó la demanda que el Secretario, junto con la citación, envió al Rmo. Z. 
Memoriali a Cl.ma Advocata ex officio die 1 septembris 2015 porrecto atque libelli inde retractatione ad normam art. 113, $\$ 2$ Legis propriae a Rev.mo Promotore Iustitiae peracta, Rev.mus Z per eandem $\mathrm{Cl}$.mam Patronam postremus scripsit.

Quibus praehabitis,

\section{SUPREMUM SIGNATURAE APOSTOLICAE TRIBUNAL}

Praemisso quod, data Cl.mo T facultate actionem contentiosam ad expensas repetendas in causa disciplinari exercendi ad modum saltem per analogiam praescriptorum cann. 1729-1731, nec pars conventa nec Cl.mus eiusdem Advocatus petitam notam honorarii Cl.mi Advocati D.ni Y articulatim confectam et apocham soluti honorarii porrexit, sine quibus, ut par est, actio contentiosa institui nequit, et facto in casu nec instituta est;

Prae oculis habito officio quo iudex, quippe qui et munus Vicarii iudicialis praestet, adstringitur, leges nempe processuales earumque normas exsecutorias ad amussim servare, nedum quarum violatio vitium insanabilis nullitatis sententiae constituit, sed etiam quarum transgressio vitium sanabilis nullitatis sententiae parit vel meram, uti aiunt, irregularitatem constituit;

Pro comperto habito quod decretum rotale die 16 ianuarii 2013 latum certo constare edixit de nullitate sententiae, Rev.mo $\mathrm{Z}$ praeside, prolatae ob Cl.mo $\mathrm{T}$ denegatum ius defensionis $\ll$ ob absentiam publicationis aliquorum processus actorum, speciatim aliquorum testimoniorum»;

Cum vitium de quo, id est illegitima publicatio actorum, causam unicam, consciam et efficacem in Rev.mi $Z$ actione ac voluntate habeat, quippe qui:
Presentado el escrito de la Abogada ex officio el día 1 de septiembre de 2015 y realizada por lo tanto la retractación de la demanda según el art. $113, \S 2$ de la Ley propria por el Rmo. Promotor de Justicia, el Rmo. Z finalmente escribió a través de su Abogada.

Con todo esto,

\section{EL SUPREMO TRIBUNAL DE LA SIGNATURA APOSTÓLICA}

Teniendo presente que, con la facultad dada al Sr. T de ejercer la acción contenciosa mediante una causa disciplinar para recuperar los gastos, en analogía de lo prescrito en los cánones 17291731; ni la parte demandada, ni su Abogado han entregado la solicitada factura desglosada de los honorarios del Abogado Sr. Y, ni el recibo de su pago, sin los cuales, como es evidente, no puede instruirse una acción contenciosa y, de hecho, en este caso no se ha instruido;

Habida cuenta que el oficio por el que el juez, ya que cumple el oficio de Vicario judicial, está obligado a guardar escrupulosamente las leyes procesales y sus normas ejecutorias, no sólo porque la violación de éstas constituye un vicio insanable de nulidad de la sentencia, sino también porque su transgresión genera un vicio sanable de nulidad de la sentencia o bien, como se dice, constituye una irregularidad;

Teniendo por cierto que el decreto rotal dado el día 16 de enero de 2013 manifestó que constaba la nulidad de la sentencia dada, siendo presidente el Rmo. Z, por la denegación del derecho de defensa al Sr. $T$ «por la ausencia de publicación de algunas actas del proceso, especialmente de algunos testimonios»;

Como el vicio de la ilegítima publicación de las actas tiene su única, consciente y eficaz causa en la voluntad y actuación del Rmo. Z, ya que: 
- haud obstante commercio epistulari cum Cl.mo partis conventae Advocato instituto, praescripta can. 1598 et art. 229, $\$ 3$ Instructionis Dignitatis connubii servare noluerit;

- monitioni generali ab hac Signatura Apostolica die 17 septembris 2011 recepta obtemperare pariter noluerit;

Attento quod in excusationem adduci nequeunt:

- praxis in Tribunalibus Civitatum Foederatorum Americae Septentrionalis passim sueta, quaedam nempe acta partibus non publicandi, quae praxis in consuetudinem non vertit, saltem ob frequentiores a Codice promulgato interventus competentis auctoritatis ecclesiasticae praefatam praxim damnantes, inter quos annumerari queunt Allocutio Summi Pontificis ad Rotam Romanam anno 1989 habitam et Instructio Dignitas connubii servanda a Tribunalibus dioecesanis et interdioecesanis in pertractandis causis nullitatis matrimonii anno 2005 publicata;

- iurisprudentia rotalis, quasi decretum rotale de quo par non sit iurisprudentiae communi et constanti Rotae Romanae; nam ipsum decretum rotale coram Colagiovanni, die 12 octobris 1993 in una Camdensi latum atque a Cl.ma Rev.ma Z Patrona pluries relatum, quin constituat iurisprudentia rotalis, principium servat quod dein in articulo 231 praefatae Instructionis sancitur, iuxta quod violatio praescripti can. 1598, $\$ 1$ nullitatem sententiae parit aut vitio sanabili (cfr. can. 1622, n. 5) aut vitio insanabili ex iure defensionis denegato (cfr. can. 1620, n. 7); periculo, proinde, alterutriusque vitii suam activitatem iudex exponere nequit absque gravi sui officii proditione;
- a pesar del intercambio epistolar con el Abogado de la parte demandada, no quiso seguir lo prescrito en el can. 1598 y en el art. $229, \$ 3$ de la Instrucción Dignitas connubii;

- igualmente, no quiso someterse a la advertencia general de esta Signatura Apostólica recibida el 17 de septiembre de 2011;

Teniendo en cuenta que no puede aducirse como justificación:

- la praxis acostumbrada en los Tribunales de los Estados Unidos, a saber, de no publicar algunas actas procesales a las partes; praxis que no se convierte en costumbre, $\mathrm{y}$ menos por las recurrentes intervenciones de la competente autoridad eclesiástica desde la promulgación del Código reprobando dicha praxis, entre las cuales se pueden contar el Discurso del Romano Pontífice a la Rota Romana del año 1989 y la Instrucción Dignitas connubii publicada en el año 2005 para ser observada por los Tribunales diocesanos e interdiocesanos en el tratamiento de las causas de nulidad del matrimonio;

- la jurisprudencia rotal, como si el decreto rotal en causa no fuese coherente con la jurisprudencia común y constante de la Rota Romana; pues el mismo decreto rotal coram Colagiovanni, del día 12 de octubre de 1993 dado en una Camdensi y citado varias veces por la Abogada del Rmo. Z, sin que constituya jurisprudencia rotal, mantiene el principio, que después sanciona el artículo 231 de la mencionada instrucción, y según el cual, la violación de lo prescrito por el can. $1598, \$ 1$ provoca la nulidad de la sentencia o por un vicio sanable (cfr. can. 1622, n. 5) o por un vicio insanable a consecuencia de la denegación del derecho de defensa (cfr. can. 1620, n. 7); por tanto, el juez por el peligro de uno u otro vicio no puede realizar su actividad sin un grave perjuicio a su función; 
- servata advocato publicatio actorum, nam praescriptum can. $1598, \$ 1$ haud inepte explicite cavet de inspectione actorum a iudice decreto «partibus et advocatis» permissa.

Cum de bona fide Rev.mi $Z$ sermo ne quidem esse potest ratione habita sive scientiae seu tituli academici in iure canonico sive monitionum generalium et singularis ad rem eidem Rev.mo Viro datarum;

Vi art. 113, $\$ 2$ Legis propriae H.S.T.;

Re sedulo considerata in Congressu coram infrascripto Cardinali Praefecto die 29 octobris 2015 habito,

\section{decrevit:}

Rev.mum D.num $Z$ monendum esse atque facto moneri ne in posterum praescripta can. 1598, $\$ 1$ (cfr. artt. 229234 Instructionis Dignitas connubii) transgredi praesumat;

Eundem Rev.mum Virum mulcta 1.500 dollariorum americanorum, in arca H.S.T. intra diem 31 decembris 2015 solvenda, plectendum esse et facto plecti.

Rev.mus $Z$ apud arcam H.S.T. solvere tenetur summam 500 dollariorum americanorum pro emolumento Cl.mae Patronae ex officio, necnon summam 300 dollariorum americanorum pro expensis processualibus.

Quae decisio cum omnibus quorum interest communicetur et exsecutioni mandetur ad omnes iuris effectus.

Romae, e Sede Supremi Signaturae Apostolicae Tribunalis, die 29 octobris 2015.

\author{
Dominicus Card. MAMBERTI \\ Praefectus \\ + Franciscus DaneEls, o. praem. \\ Secretarius
}

- el que se haya mantenido la publicación de las actas para el abogado, pues el can. 1598, $\$ 1$ protege de manera explícita e inequívoca la revisión de las actas permitida por decreto del juez «a las partes y a los abogados».

Como no puede hablarse de buena fe por parte del Rmo. Z, habida cuenta de su ciencia y de su título académico en Derecho canónico, así como de las advertencias generales y particulares dadas sobre la cuestión al Rmo. Sr.;

En virtud del art. 113, $\$ 2$ de la Ley propria de la Signatura;

Considerado el asunto en el Congreso ante el infrascrito Cardenal Prefecto tenido el 29 de octubre de 2015,

\section{decretó:}

Que el Rmo. Sr. Z ha de ser advertido y de hecho será advertido para que en el futuro no viole las prescripciones del can. 1598, $\$ 1$ (cfr. arts. 229-234 de la Instrucción Dignitas connubii);

Que el Rmo. Sr. sea sancionado con una multa de 1.500 dólares americanos. Éstos deberán depositarse en la caja de este Supremo Tribunal antes del 31 de diciembre de 2015 .

El Rmo. $Z$ debe pagar en la caja de este Supremo Tribunal la cantidad de 500 dólares americanos en concepto de emolumento de la Patrono ex officio, así como la suma de 300 dólares americanos para las costas procesales.

Comuníquese esta decisión a todos los interesados y ordénese su ejecución a todos los efectos jurídicos.

En Roma, de la Sede del Supremo Tribunal de la Signatura Apostólica, en el día 29 de octubre de 2015.
Dominique Card. MAMBERTI
Prefecto
+ Frans DaneEls, o. praem.
Secretario 


\section{Comentario el Decreto 2.1}

El 16 de enero de 2013 el Tribunal de la Rota Romana decretó la nulidad de la sentencia pro nullitate del matrimonio A/T debido a irregularidades procesales que se debieron a la ilegítima publicación de las actas, por no facilitarse información a la parte demandada sobre las declaraciones de los testigos ${ }^{18}$.

Posteriormente a la recepción de dicho decreto rotal, el demandado solicitó al Obispo el reembolso de los gastos correspondientes a los honorarios de su abogado, ya que habían sido más elevados de lo previsto por las complicaciones procesales del caso, precisamente dadas las irregularidades imputables al Tribunal. Tras la respuesta negativa del Obispo C, el demandado recurrió la denegación a la Signatura Apostólica.

El Alto Tribunal consideró que el demandado tenía la facultad de exigir la restitución de los gastos, haciendo una analogía con lo establecido en los cc. 1729-1731. No obstante, finalmente desestimó instruir el recurso administrativo al no haberse presentado pruebas suficientes sobre el detalle de los honorarios, ni evidencias de que se hubiera realizado tal pago. Sin embargo, tras examinar las actas del proceso matrimonial de A/T, el Tribunal de la Signatura decidió proceder ex officio en una causa disciplinar contra los miembros del Tribunal de primera instancia.

Estamos en uno de los supuestos previstos en el art. 113 de la LP del Tribunal de la Signatura Apostólica, concretamente ante una causa administrativa disciplinar ex officio.

Según se deduce del texto del Decreto, se considera que el Vicario judicial ha cometido una serie de ilícitos administrativos que merecen ser sancionados:

a) El haber incumplido la obligación de guardar escrupulosamente las leyes procesales y sus normas ejecutorias;

b) el haber impedido el ejercicio del derecho de defensa de la parte demandada, ya que no se publicaron algunas actas del proceso, especial-

${ }^{18}$ Como señala el c. 1680, $\$ 1$, Mitis Iudex Dominus Iesus (MIDI) «Permanece íntegro el derecho de la parte que se considere perjudicada, así como del promotor de justicia y del Defensor del vínculo, de interponer querella de nulidad o apelación contra la misma sentencia, según los cc. 1619-1640». Con la querella se impugnan las resoluciones que adolecen de algún vicio de nulidad (cc. 1620 y 1622). 
mente en relación a los testimonios; esto se desprende del hecho de que sólo se haya dado acceso a las actas al abogado. El c. 1598, $\$ 1$ establece que «el juez, mediante decreto debe permitir, bajo pena de nulidad, que las partes y sus abogados examinen en la cancillería del tribunal las actas que aún no conocen; e incluso se puede entregar copia de las actas a los abogados que la pidan...». Sigue diciendo el canon citado: «El juez, para evitar peligros gravísimos, puede decretar que algún acto no sea manifestado a nadie, teniendo cuidado de que siempre quede a salvo el derecho de defensa». Sin embargo, no parece que ésta haya sido la causa de la parcial e ilegítima publicación de las actas ${ }^{19}$.

Además, en cuanto a la imputabilidad del Vicario Judicial, se considera que ha procedido con mala fe, puesto que no atendió a las peticiones por escrito del abogado de la parte demandada; tampoco siguió una Recomendación general del Tribunal de la Signatura de 17 de septiembre de 2011 -a la que no me ha resultado posible acceder-, ni tuvo en cuenta las reiteradas afirmaciones de los decretos rotales en contra de la limitación del derecho de defensa. Aunque el decreto no lo mencione, el art. 35 de la Dignitas connubii establece que «todos los que forman parte del tribunal o colaboran con él han de prestar juramento de que cumplirán su función del modo debido y fielmente (c. 1454). (...) 3. Conviene, de manera especial, que estudien la jurisprudencia de la Rota Romana, ya que a ésta le corresponde velar por la unidad de la jurisprudencia y servir de ayuda a los tribunales inferiores mediante sus sentencias (cfr. Pastor bonus, art. 126)». Al poseer un título de Derecho Canónico, entiende la Signatura que el Vicario Judicial estaba en condiciones de advertir la ilegitimidad de su actuación.

Por último, no cabe alegar que exista una costumbre válida contra legem en el país donde se desarrollan los hechos, aunque esté extendida tal praxis, en relación a la publicación parcial de las actas.

En este caso, el hecho de que se imponga al Vicario Judicial una sanción pecuniaria puede suscitar interés. Por una parte, se le hace una amonestación

${ }^{19}$ En los procesos matrimoniales, la Dignitas connubii establece igualmente que el juez debe proceder a la publicación de las actas mediante decreto del juez por el que se concede a las partes y a sus abogados la facultad de examinarlas (art. 229). En el art. 230 se permite que el juez pueda decretar que algún acto no sea manifestado a las partes, siempre que quede a salvo el derecho de defensa. El art. 231 establece que la denegación del derecho de defensa, implica la nulidad insanable de la sentencia. 
escrita para que en el futuro no vuelva a violar las normas procesales, pero además se le impone una multa pecuniaria de 1.500 dólares; se le requiere además el reembolso de 500 dólares por los honorarios del Patrono de oficio y 300 dólares en concepto de costas procesales.

En el caso de las sanciones disciplinares, la privación impuesta suele hace relación directa al oficio. El Derecho canónico contempla la posibilidad de aplicar las multas, como sanciones que privan de un bien temporal -una cantidad de dinero-, como consecuencia de una actuación antijurídica, aunque el legislador universal sólo las haya previsto explícitamente en dos cánones del $\mathrm{CIC}^{20}$. En primer lugar se recoge la posibilidad de imponer multas pecuniarias por parte del juez cuando haya compra del pleito o emolumentos excesivos por parte del procurador o abogado; también si por promesas, regalos, o por cualquier otra razón aquéllos prevaricaren de su oficio (cc. 1488 y 1489). La multa también aparece explícitamente recogida en los arts. 70 y 71 del RGCR, como una sanción disciplinar ${ }^{21}$.

La Lex propria de la Signatura Apostólica no especifica qué sanciones disciplinares administrativas se podrán imponer. En defecto de tal determinación, habrá que tener en cuenta lo que establece el recién mencionado art. 70 del Reglamento General de la Curia Romana ${ }^{22}$. El artículo enumera como sanciones disciplinares: 1) la amonestación oral, la advertencia escrita y la multa pecuniaria; 2) la suspensión del oficio; 3 ) excedencia del oficio; 4) el despido del oficio; 5) y la destitución de derecho ${ }^{23}$.

${ }^{20}$ Frente a la escasa presencia de la multa en el CIC vigente, ésta venía contemplada en el CIC 17 como una pena vindicativa, que actualmente denominamos expiatoria (c. 2291, 12 $2^{\mathrm{a}}$. El Código preveía esta pena para varios delitos. En el c. 2406, donde se contemplaba la negativa dolosa a facilitar copias, transmitir o mostrar actas, documentos, o libros o faltando al deber, reconocía la posibilidad de imponer una multa además de la privación o suspensión del oficio, según la gravedad del caso. El Código de Derecho canónico de 1983 no considera las multas como sanciones penales, aunque no se pronuncia explícitamente sobre cuál es su naturaleza jurídica. De ahí, que desde un punto de vista doctrinal, podamos afirmar su naturaleza administrativa. V. DE PAOLIS - D. CiTo, Le sanzioni nella Chiesa. Commento al Codice di diritto canonico, Vol. VI, Città del Vaticano 2000; J. MiRAS - J. CANOSA - E. BAURA, Compendio de derecho administrativo canónico, Pamplona 2001, 119; F. PÉREZ-MADRID, Derecho administrativo sancionador en el ordenamiento canónico, Pamplona 1994, 194.

21 F. PÉrez-Madrid, voz «Sanción», en J. Otaduy - A. Viana - J. Sedano (eds.), Diccionario General de Derecho canónico, III, Thomson Reuters Aranzadi, Cizur Menor (Navarra) 2013.

${ }^{22}$ Igualmente el c. 1488 y el c. 1489, así como el art. 5, 1 del MP Iusti iudicis.

$23 \mathrm{~J}$. CANOSA, Il procedimento amministrativo disciplinare previsto in alcuni regolamenti vigenti nella Curia Romana, en D. Cito (cur.), Processo penale e tutela dei diritti nell'ordinamento canonico, Milano 2005, 433-448; Á. MarzoA, Sanciones disciplinares y penas canónicas, Ius Canonicum 28 
Lo sorprendente es que en el art. 71 del RGCR se establezca como límite máximo para las multas pecuniarias «la retribución de dos jornadas de trabajo» ${ }^{24}$, una precisión que puede privar a las multas, al menos en algunos casos, de su verdadero carácter sancionador ${ }^{25}$.

En este caso, la multa impuesta de 1500 dólares excede ampliamente el límite máximo previsto reglamentariamente para la Curia Romana, por lo que cabe plantearse si es razonable o por el contrario es una multa excesivamente elevada ${ }^{26}$. A título de ejemplo, la Ley Orgánica del Poder Judicial de España establece que se pueden imponer multas a los Jueces y Magistrados por las faltas cometidas en el ejercicio de sus cargos, que en casos graves podrá llegar a ser de 6.000 euros. Por tanto, con los datos que nos aporta el decreto, no parece a primera vista que la multa tenga una cuantía desproporcionada, especialmente teniendo en cuenta la intencionalidad y el perjuicio causado, y que en cualquier caso, es inferior a la cantidad que el demandado había solicitado como reembolso de sus gastos.

Cuando se pretende preservar la disciplina canónica, también se defiende la salus animarum. «El derecho -señaló Pablo VI- no es un impedimento, sino una ayuda pastoral; [...] Su tarea específica no consiste en reprimir y oponerse, sino en estimular, promover, proteger y defender el espíritu de la verdadera libertad $\gg^{27}$.

(1988) 181-196; J. Miras, Derecho al buen gobierno en la Iglesia. Una glosa a la doctrina constitucional de Favier Hervada desde el Derecho Administrativo, en AA. Vv., Escritos en honor de Favier Hervada, Pamplona 1999, 367-377; Studium Romanae Rotae (P. V. Pinto [ed.]), Corpus Iuris Canonici. III. Commento alla Pastor bonus e alle norme sussidiarie della Curia Romana, Roma 2003, 412-430.

${ }^{24}$ En el mismo sentido, el Reglamento del Vicariato de Roma del año 2000, en su art. 78.

25 Como dice Baura, la multa pecuniaria siempre se ha visto como una sanción disciplinar en la medida en que incide sobre el salario o pago por la propia actividad, y por tanto queda encuadrada en el ámbito propio de las tareas del cargo. Cfr. E. BAURA, Art. 113 della Legge propria della Segnatura Apostolica, en M. DEL POZZO - J. Llobell - J. MiÑAMbres (a cura di), Norme procedurali canoniche, Roma 2013, 124-125.

${ }^{26}$ En el texto este Decreto de la Signatura Apostólica se dice que el caso proviene de Estados Unidos, un dato que permite valorar la proporcionalidad de la sanción según el nivel de vida del país. En 2017, el salario mínimo interprofesional era de 1192 euros, mientras que en España era de 707 euros.

27 Cfr. los comentarios de A. VALLINI, La función pastoral del Supremo Tribunal de la Signatura Apostólica en la vigilancia sobre los tribunales eclesiásticos, Ius Communionis I (2013) 203-220. 


\subsection{Decreto de la Signatura Apostólica dirigido contra el Defensor del vínculo Rdo. $S$}

Prot. N. 48706/14 VT

Disciplinaris

(Rev.dus S)

Occasione provocationis ad H.S.T. ex parte Cl.mi T adversus denegatam expensarum iudicialium restitutionem, haec Signatura Apostolica acta iudicialia omnia causae nullitatis matrimonii $\mathrm{A} / \mathrm{T}$ in foro $\mathrm{C}$ in primo iurisdictionis gradu agitatae atque definitae acquisivit atque examini subiecit.

In qua causa quibusdam irregularitatibus ex parte Rev.di Defensoris vinculi patratis inventis, Rev.mus Promotor Iustitiae, causa disciplinari apud H.S.T. instituta, libellum causae introductorium porrexit, quem Exc.mus Secretarius una cum citatione ad Rev.dum D.num S misit.

Memoriali a Cl.ma Advocata ex officio die 1 septembris 2015 porrecto atque libelli inde retractatione ad normam art. $113, \$ 2$ Legis propriae a Rev.mo Promotore Iustitiae peracta, Rev.dus S per eandem Cl.mam Patronam postremus scripsit.

Quibus praehabitis,

\section{SUPREMUM SIGNATURAE APOSTOLICAE TRIBUNAL}

Prae oculis habito officio quo Defensor vinculi ad normam iuris adstringitur, id est «proponendi et exponendi omnia quae rationabiliter adduci possint adversus nullitatem» (can. 1432), seu «proponendi cuiuslibet generis probationes, oppositiones et exceptiones, quae, servata rei veritate, ad vinculi tuitionem conferant $\gg$ (art. 56, $\$ 3$ Instructionis Dignitas connubii);
Prot. N. 48706/14 VT

Disciplinar

(Rdo. S)

Con motivo del recurso ante este $\mathrm{Su}$ premo Tribunal por parte del sr. T contra la denegación de la devolución de los gastos judiciales, esta Signatura Apostólica obtuvo todas las actas judiciales de la causa de nulidad de matrimonio A/T tratada en primer grado de jurisdicción en el Tribunal $\mathrm{C}$ y las examinó.

Halladas en esta causa algunas irregularidades realizadas por parte del Rdo. Defensor del vínculo, el Rmo. Promotor de Justicia, iniciada la causa disciplinar en este Tribunal, presentó el escrito de demanda que el Secretario envió al Rdo. Sr. S junto con la citación.

Presentado el escrito por parte de la Abogada ex officio el 1 de septiembre de 2015 y realizada la retractación de la demanda por parte del Rmo. Promotor de Justicia según el art. 113, $\$ 2$ de la Ley propria, el Rdo. S. en último lugar respondió por medio de la Abogada.

Consideradas estas cosas,

\section{EL SUPREMO TRIBUNAL DE LA SIGNATURA APOSTÓLICA}

Habida cuenta del oficio al cual está obligado el Defensor del vínculo según el derecho, es decir, a «proponer y manifestar todo aquello que puede aducirse razonablemente contra la nulidad» (can. 1432), o bien a «proponer cualquier tipo de pruebas, oposiciones y excepciones que, respetando la verdad de los hechos, contribuyan a la defensa del vínculo» (art. 56, $\$ 3$ de la Instrucción Dignitas connubii); 
Pro comperto habito quod, tot tantisque contentionibus inter iudicem et partem conventam quoad legitimam publicationem actorum habitis, vix ne vix quidem officio Defensoris vinculi par concipi potest usus cuiusdam formularii praeconstituti vi cuius idem Defensor vinculi super iisdem contentionibus nullam prorsus animadversionem, immo ne quidem mentionem, promat;

Praetermissis aliis in eundem Defensorem vinculi animadvertendis ob iteratum eiusdem formularii praeconstituti usum in eadem causa post declaratam sententiae nullitatem, coram eodem foro $\mathrm{C}$ pertractata, in quo ceterum declaratur etiam appellationi renuntiatio antequam sententiae exaratio, immo eiusdem prolatio habeatur;

In mente autem retenta provecta Rev.di S aetate;

Vi art. 113, \$2 Legis propriae H.S.T.;

Re sedulo considerata in Congressu coram infrascripto Cardinali Praefecto die 29 octobris 2015 habito,

decrevit:

Rev.dum D.num S invitandum esse atque invitari ut muneri Defensoris vinculi in foro $\mathrm{C}$ ante diem 31 decembris 2015 abrenuntiet;

Adversus eundem Rev.dum Virum, propositam renuntiationem abnegantem, post diem 31 decembris 2015 processum disciplinarem per amotionem a munere Defensoris vinculi perficiendum esse;

Eundem Rev.dum Virum monendum esse et facto moneri ut officia Defensoris vinculi usque ad praefatam muneris cessationem adamussim obeat.
Habiendo considerado que, han existido muchas controversias entre el juez y la parte demandada en relación con la legítima publicación de las actas, a duras penas puede concebirse en el oficio del Defensor del vínculo el uso de un formulario preconstituido en virtud del cual el mismo Defensor del vínculo no haga sobre estas controversias el más mínimo comentario, es más ni siquiera haga mención;

Dejando aparte otras cuestiones susceptibles de corregir sobre el citado Defensor del vínculo por reiterado uso del mismo formulario preconstituido en la misma causa después de declarada la nulidad de la sentencia, tratada ante el mismo tribunal C, en el que, además, se declara la renuncia a la apelación antes de que se tenga el escrito de la sentencia e incluso antes de su comunicación;

No descuidando la avanzada edad del Rdo. Sr. S;

En virtud del art. 113, \$2 de la Ley propria de este Supremo Tribunal;

Considerada atentamente la cuestión en el Congreso tenido el 29 de octubre de 2015 ante el infrascrito Cardenal Prefecto,

\section{decretó:}

Que el Rdo. Sr. S ha de ser invitado, y es invitado, a que renuncie de su cargo de Defensor del vínculo en el Tribunal $C$ antes del 31 de diciembre de 2015;

Contra el rechazo del mismo Rmo. Sr. a la renuncia propuesta, se realizará un proceso disciplinar para removerlo del cargo de Defensor del vínculo después del 31 de diciembre de 2015;

Que el mismo Rdo. Sr. sea amonestado, y de hecho es amonestado, para que asuma los encargos de Defensor del vínculo con exactitud hasta la mencionada cesación del oficio. 
Rev.dus D.nus S apud arcam H.S.T. solvere tenetur summam 500 dollariorum americanorum pro emolumento Cl.mae, Patronae ex officio, necnon summam 300 dollariorum americanorum pro expensis processualibus.

Quae decisio cum omnibus quorum interest communicetur et exsecutioni mandetur ad omnes iuris effectus.

Romae, e Sede Supremi Signaturae Apostolicae Tribunalis, die 29 octobris 2015.

\author{
Dominicus Card. MAMBERTI \\ Praefectus \\ + Franciscus DaneELs, o. praem. \\ Secretarius
}

El Rdo. Sr. S debe pagar en la caja de este Supremo Tribunal la cantidad de 500 dólares americanos por concepto de Abogado ex officio, así como la cantidad de 300 dólares americanos por las costas judiciales.

Comuníquese esta decisión a todos los interesados y ordénese su ejecución a todos los efectos jurídicos.

Roma, desde la Sede del Supremo Tribunal de la Signatura Apostólica, en el día 29 de octubre de 2015.

\section{Dominique Card. MAMBERTI Prefecto \\ + Frans DANEELS, o. praem. \\ Secretario}

\section{Comentario al Decreto 2.2}

Dentro de la misma causa disciplinar del Decreto 2.1 ya comentado, ahora la Signatura apostólica se dirige al Defensor del vínculo del Tribunal, a quien sanciona por diversas actuaciones negligentes.

Para situar la gravedad de sus acciones, vale la pena recordar unas palabras del Papa Francisco. En su discurso a la Plenaria del Tribunal Supremo de la Signatura Apostólica el 8 de noviembre de 2013 recordó que «(...) el Defensor del vínculo desempeña una función importante. (...) su presencia y su intervención son obligatorias para todo el desarrollo del proceso (...). Del mismo modo está previsto que él proponga todo tipo de pruebas, excepciones, recursos y apelaciones que, en el respeto de la verdad, favorezcan la defensa del vínculo. (...) El cumplimiento fiel y completo de la tarea del Defensor del vínculo no constituya un pretexto, en detrimento de las prerrogativas del juez eclesiástico, a quien únicamente corresponde definir la causa. Cuando el Defensor del vínculo ejerce el deber de apelar, incluso a la Rota romana, contra una decisión que considera perjudicial para la verdad del vínculo, su misión no suplanta la del juez. Es más, los jueces pueden encontrar en la esmerada actuación de quien defiende el vínculo matrimonial una ayuda a la propia actividad. El Concilio Ecuménico Vaticano II definió a la Iglesia como comunión. En esta perspectiva debe verse tanto el servicio del Defensor del vínculo como la consideración que a ello se reserva, en un respetuoso y atento diálogo». 
Actualmente en la mayor parte de las causas ambos cónyuges desean que se dicte una sentencia afirmativa al confundir el fracaso matrimonial con la nulidad del vínculo; además el Defensor del vínculo, con frecuencia, se limita a dar su parecer en la fase final de "discusión" de la causa (cfr. DC, art. 243) ${ }^{28}$. En este caso, el Rdo. S usó en la causa un formulario preconstituido donde manifestaba que renunciaba a la apelación incluso antes de conocer la sentencia $^{29}$. No tenía obligación de apelar, pero el c. 1432 establece que por oficio debe proponer y manifestar todo aquello que puede aducirse razonablemente contra la nulidad o disolución ${ }^{30}$. Una renuncia a priori supone una conducta negligente frente a los deberes anejos a su cargo.

La sanción impuesta por el decreto es la invitación a renunciar de su oficio y una amonestación; en caso de que no accediera, se determina que se procederá a la remoción por medio de un proceso disciplinar. Ciertamente, la infracción cometida por el Rdo. S es más compleja y grave que la del Vicario Judicial, desde un punto de vista meramente objetivo; ahora bien, teniendo en cuenta la edad avanzada de este Defensor del vínculo, cabe plantearse si en estos casos proceden este tipo de decretos o si bien, habría sido preferible otra vía para quizá llegar a la misma solución, el cese en sus funciones. Efectivamente, la remoción puede decidirse aun cuando no haya culpa grave del interesado. Ciertamente en este caso, podría plantearse si más que un incumplimiento culpable en las tareas encomendadas, se trataba más bien de una posible falta de idoneidad, por la que sin culpa grave del interesado, su desempeño resultaba perjudicial o al menos ineficaz, como señala el c. 1740 sobre la remoción de los párrocos; incluso también podría hablarse de impericia, de enfermedad mental o corporal, que le hacían incapaz de desempeñar útilmente sus funciones (c. 1741). También podría plantearse hasta qué punto el Obispo que le nombró

${ }^{28}$ J. LlobeLL, El valor jurídico de la instr. «Dignitas connubii», en R. RODRÍGUEZ-OCAÑA - J. SEDANO (eds.), Procesos de nulidad matrimonial. La Instrucción «Dignitas connubii», Pamplona 2006, 235 301.

29 En realidad, el CIC 1983 modificó el sistema de obligar al Defensor del vínculo a apelar en el caso descrito, que había sido establecido por Benedicto XIV, y lo sustituyó por la obligación del tribunal que dicta por vez primera una sentencia pro nullitate matrimonii de enviarla ex officio al tribunal «de apelación» (el de instancia superior, que puede ser de segunda, tercera o ulterior instancia: cfr. DC, arts. 265 1 1, 266, 268, 2). A la vez, el n. 8, 3 del Motu Proprio Causas matrimoniales dispuso que, si esa sentencia era de primera instancia, el tribunal superior (pudiera confirmarla mediante un decreto).

${ }^{30}$ Para todas estas cuestiones, cfr. M. A. ORTIZ, Il difensore del vincolo, en La nullità del matrimonio: temi processuali e sostantivi in occasione della «Dignitas connubii», 27-68; R. RODRÍGUEZ-OCAÑA, La demanda judicial canónica, Pamplona 2002, passim. 
o le mantuvo en el cargo, tenía el deber y la responsabilidad de aseguar que podía ejercer su oficio con probada prudencia y celo por la justicia (c. 1435).

Pues bien, en la medida en que es necesario tutelar el bien público cuando exista el riesgo de un perjuicio a la autoridad, a las funciones, no se puede excluir el ejercicio de la potestad sancionadora ya que está también en juego el posible daño a los derechos o los bienes de los particulares, en relación con la misión de la Iglesia de salvar las almas ${ }^{31}$.

Por último, el Decreto no incluye cláusula alguna que asegure o recuerde al Obispo diocesano la previsión del c. 195: «Si alguien es removido de un oficio con el que se proveía a su sustento, no de propio derecho, sino por decreto de la autoridad competente, la misma autoridad debe cuidar de que se provea por tiempo conveniente a su sustento, a no ser que se haya provisto de otro modo» ${ }^{32}$. El canon no reconoce que en este caso exista una obligación jurídica, pero podría haberse hecho alguna referencia en el Decreto dada la perentoriedad de la sanción adoptada que deberá materializarse en el término de dos meses.

\section{LA REMOCIÓN DEL OFICIO DE VICARIO JUDICIAL POR LA PERDIDA DE LA ÍNTEGRA FAMA (PROT. N. 48191/13 VT)}

\subsection{Recurso jerárquico ante el Tribunal de la Signatura Apostólica por la remoción de oficio de un Vicario judicial}

\author{
Prot. N. 48191/13 VT \\ Amotionis ab officio \\ (Rev.dus V)
}

\author{
Prot. N. 48191/13 VT \\ De remoción del oficio \\ (Rdo. V)
}

\section{DECRETUM}

Decreto diei 29 iunii 2012 Exc.mus Episcopus D Rev.dum V, presbyterum Dioecesis D, ad officium Vicarii iudicialis ad quinquennium nominavit, at vero eum iam die 29 maii $2013 \mathrm{ab}$ hoc officio amovit.

\section{DECRETO}

Mediante el decreto de 29 de junio de 2012, el Obispo D nombró al Rdo. $\mathrm{V}$, presbítero de la Diócesis D, para el oficio de Vicario judicial por el periodo de un quinquenio. Sin embargo, le removió del oficio el 29 de mayo de 2013.

31 Cfr. I. ZuanazzI, voz «Bien público», en J. OtaduY - A. Viana - J. Sedano (eds.), Diccionario General de Derecho canónico, III, Thomson Reuters Aranzadi, Cizur Menor (Navarra) 2013, 738-735.

32 En el caso de los párrocos, el c. 1746 establece: «El Obispo ha de proveer a las necesidades del párroco removido, bien confiándole otro oficio, si es idóneo, o mediante una pensión, según lo aconseje el caso y lo permitan las circunstancias». 
Quam adversus amotionem Rev.dus Presbyter die 3 iunii 2013 remonstrationem interposuit, qua reiecta, die 12 iulii 2013 coram hac Signatura Apostolica hierarchicum proposuit recursum.

Audito Exc.mo Moderatore Fori Dioecesani D et Rev.do V data facultate patronum nominandi, qua facultate ipse usus non est,

\section{SUPREMUM SIGNATURAE APOSTOLICAE TRIBUNAL}

Perpenso quod sufficienter ex actis probatae sunt sat magnae expensae, haudquaquam in exercendis muneribus suis a Rev.do Recurrente sumptibus dioecesis factae;

Cum exinde deficiat illa integra fama, quae ad officium Vicarii iudicialis can. 1420, \$ 4 requiritur, cumque exinde legitima gravisque causa habeatur ad eum ab hoc officio amovendum (cfr. can. 1422);

Attento quod iuxta constantem H.S.T. iurisprudentiam sufficit ut una ex causis in decreto amotionis adductis vera et gravis sit;

Ad petitam refectionem asserti damni oeconomici quod attinet, animadverso quod haec quaestio ne ponitur quidem, eo quod de actus impugnati illegitimitate haud constat;

Praetermissis aliis forte animadvertendis;
El Rdo. Presbítero interpuso remonstratio ${ }^{33}$ contra esta remoción el día 3 de junio de 2013. Una vez rechazado éste, presentó ante esta Signatura Apostólica un recurso jerárquico.

Oído el Moderador del Tribunal Diocesano D y dada al Rdo. V la facultad de nombrar un patrono -facultad que no empleó-,

\section{EL SUPREMO TRIBUNAL DE LA SIGNATURA APOSTÓLICA}

Valorado que, de las actas, han sido suficientemente probados los grandes gastos, hechos por el Rdo. Recurrente con cargo a la diócesis y en modo alguno concernientes al ejercicio de sus oficios;

Ya que viene a menos la íntegra fama que se requiere para el Oficio de Vicario judicial según el c. 1420, \$ 4, y que se da la causa legítima y grave para removerlo de ese oficio (cfr. can. 1422);

Considerado que, según la constante jurisprudencia de este Supremo Tribunal, basta que una de las causas aducidas en el decreto de remoción sea verdadera y grave;

En lo que se refiere a la petición del resarcimiento del mencionado daño económico, observado que esta cuestión ciertamente no se plantea, ya que no consta la ilegitimidad del acto impugnado;

Dejando aparte otras consideraciones;

33 En la publicación de decisiones de la Signatura que hace Wilson \& Lafleur, no suele traducir esta palabra. Define la remonstratio como el término, no presente en el CIC, empleado por la jurisprudencia para aludir a la petición de revocación o corrección de la decisión dada por la autoridad competente -cfr. c. 1734- (cfr. TSSA, Ministerium Iustitiae: Furisprudence of the Supreme Tribunal of the Apostolic Signatura: official Latin with English translation, Montréal 2011, 359, nota al pie). 
Vi art. 124, n. 1 Const. Apost. Pastor bonus et art. 114, $\$ 1$ conlati cum art. 107, 1 Legis propriae H.S.T.;

Re sedulo examini subiecta in Congressu, die 20 septembris 2013 coram infrascripto Praefecto habito,

decrevit:

Recursum hierarchicum reiciendum esse et facto reici.

Et notificetur omnibus quorum interest, ad omnes iuris effectus.

Datum Romae, e sede Supremi Signaturae Apostolicae Tribunalis, die 20 septembris 2013.

Raimundus Leo Card. BURKE

Praefectus

+ Franciscus DaneEls, o. praem.

Archiepiscopus tit. Bitensis

Secretarius
En virtud del art. 124, $\mathrm{n}^{\circ} 1$ de la Const. Apost. Pastor bonus y del art. $114, \$ 1$ en relación con el art. $107, \$ 1$ de la Ley propria de este Tribunal;

Sometida la causa al diligente examen del Congreso tenido el 20 de septiembre de 2013 ante el infrascrito Prefecto,

decretó:

Que el recurso jerárquico debe ser rechazado y de hecho se rechazó.

$\mathrm{Y}$ notifíquese a todos los interesados, a todos los efectos del derecho.

Dado en Roma, desde la sede del Supremo Tribunal de la Signatura Apostólica, el 20 de septiembre de 2013

Raymond Leo Card. BURKE

Prefecto

+ Frans Daneels, o. praem.

Arzobispo titular de Bita

Secretario

\subsection{Petición de revocación del Decreto al Prefecto del Tribunal de la Signatura Apostólica}

Prot. N. 48191/13 VT

Amotionis ab officio

(Rev.dus V)

\section{DECRETUM}

Decreto die 20 septembris 2013 in Congressu lato Em.mus H.S.T. Praefectus recursum hierarchicum Rev.di $\mathrm{V}$, presbyteri Dioecesi D incardinati, adversus decretum amotionis ab officio Vicarii iudicialis diei 29 maii 2013 reiecit.

Quo decreto die 7 octobris 2013 recepto, Rev.dus V die 11 octobris 2013,
Prot. N. 48191/13 VT

De remoción del oficio

(Rdo. V)

\section{DECRETO}

Mediante el decreto dado en el Congreso de 20 de septiembre de 2013, el Prefecto de este Supremo Tribunal rechazó el recurso jerárquico del Rdo. $\mathrm{V}$, presbítero incardinado en la diócesis $\mathrm{D}$ contra el decreto de remoción del oficio de Vicario judicial del 29 de mayo de 2013.

El 7 de octubre de 2013, al recibir este decreto, el Rdo. V, el día 11 de oc- 
invocato art. 114, $\$ 2$ Legis propriae H.S.T., revocationem decreti ab Em.mo H.S.T. Praefecto expostulavit.

Qua petitione novae audientiae attente examinata,

\section{SUPREMUM SIGNATURAE APOSTOLICAE TRIBUNAL}

Praemisso quod obiectum instantiae est praefatum decretum diei 20 septembris 2013, quod tantum de amotione ab officio Vicarii iudicalis, minime a ceteris officiis, egit;

Ad assertam violationem iuris defensionis, perpenso quod:

- inspectio actorum ante decretum amotionis, remonstrationem et in recursu hierarchico, iure quo utimur, haud requiritur (cfr. cann. 50-51 et 193, $\$ 4)$;

- ex remonstratione et dein ex recursu hierarchico evincitur Rev.dum Recurrentem tam in remonstratione quam in recursu exhibendo hierarchico causam, de qua in impugnato decreto diei 20 septembris 2013, bene novisse et sese ad rem defendisse;

- quam ob rem in casu de iure defensionis violato nequit esse sermo;

Ad assertam violationem legis in decernendo, perspecto quod:

- iuxta constantem H.S.T. iurisprudentiam sufficit ut una ex causis in decreto amotionis ab officio adductis vera et gravis sit;

- quidquid dicit Rev.dus Recurrens, saltem pro nonnullis itineribus $\mathrm{ab}$ eo peractis sufficienter ex actis probatae sunt magnae expensae haudquaquam in exercendis suis muneribus a Rev.do Recurrente sumptibus dioecesis factae, tubre, aduciendo el art. 114, $\$ 2$ de la Ley propria de este Supremo Tribunal, pidió la revocación del decreto al Prefecto de este Supremo Tribunal.

Examinada atentamente esta petición de nueva audiencia,

\section{EL SUPREMO TRIBUNAL DE LA SIGNATURA APOSTÓLICA}

Teniendo presente que el objeto de la petición es el mencionado decreto del 20 de septiembre de 2013, que sólo trató de la remoción del oficio de Vicario judicial y no de otros oficios;

En relación con la alegada violación del derecho de defensa, habida cuenta de que:

- el examen de las actas antes del decreto de remoción y de la remonstratio e incluso durante el recurso jerárquico, no se requiere de acuerdo con el derecho vigente (cfr. cann. 50-51 y 193, \$4);

- de la remonstratio y, además, del recurso jerárquico, se desprende que el Rdo. Recurrente, tanto en la remonstratio como en la presentación del recurso jerárquico, conocía bien la causa sobre el decreto impugnado del 20 de septiembre de 2013 y se defendió convenientemente;

- por tanto, en este caso no se puede hablar de violación del derecho de defensa;

En cuanto a la alegada violación de la ley in decernendo, teniendo en cuenta que:

- según la constante jurisprudencia de este Supremo Tribunal, basta que una de las causas mencionadas en el decreto de remoción del oficio sea verdadera y grave;

- lo dicho por el Rdo. Recurrente, al menos en lo que se refiere a algunos viajes realizados por él, quedan suficientemente probados, a partir de las actas, los grandes gastos hechos con cargo a la diócesis por el Rdo. Recu- 
tempore quo munere Vicarii iudicialis fungebatur;

- deficit exinde illa integra fama, quae ad officium Vicarii iudicialis can. 1420, $\$ 4$ requiritur, nam is, cui munus iudicandi tamquam Vicario Episcopi stabiliter collatum est, ab omni suspicione defectus integritatis immunis esse debet;

- quae amissio integrae famae sufficit pro amotione, et non requiritur ut orta sit ex ipso exercitio muneris Vicarii iudicialis, neque ut reapse divulgata sit;

- rebus sic stantibus, legitima gravisque causa ad eum ab officio Vicarii iudicialis amovendi satis probata habenda est;

Cum in casu nullum par adducatur argumentum ad rationes motivas in praefato decreto in H.S.T. Congressu diei 20 septembris 2013 prolatas submovendas;

Praetermissis aliis forte ad rem animadvertendis;

Vi art. 124, n. 1 Const. Apost. Pastor bonus et art. 114, \$2 H.S.T. Legis propriae;

Re sedulo examini subiecta in Congressu, die 27 februarii 2014 coram infrascripto Praefecto habito,

\section{decrevit:}

In decisis.

Et notificetur omnibus quorum interest, ad omnes iuris effectus.

Datum Romae, e sede Supremi Signaturae Apostolicae Tribunalis, die 27 februarii 2014.

Raimundus Leo Card. BuRKE

Praefectus

+ Franciscus DaneEls, o. praem.

Archiepiscopus tit. Bitensis

Secretarius rrente en ningún modo relacionados con su oficio, mientras desempeñaba el oficio de Vicario judicial;

- falta, por consiguiente, la integra fama que se requiere para el oficio del Vicario judicial (can. 1420, \$4), pues aquel a quien se le da establemente el oficio de juzgar como Vicario del Obispo, debe ser inmune de toda sospecha de falta de integridad;

- esta pérdida de la integra fama basta para la remoción, y no se requiere que haya surgido por el propio ejercicio del cargo de Vicario judicial, ni que realmente se haya divulgado;

- estando así las cosas, la causa legítima y grave para la remoción del oficio se tiene por suficientemente probada;

Como en este caso no se aducen razones adecuadas para rechazar las razones motivas dadas en el Congreso de este Supremo Tribunal del 20 de septiembre mediante el mencionado decreto;

Dejando aparte otro tipo de consideraciones;

En virtud del art. 124, n. 1 de la Const. Apost. Pastor bonus y del art. 114, $\$ 2$ de la Ley propria de este Supremo Tribunal;

Sometida la cuestión a examen en el Congreso del día 27 de febrero de 2014 tenido ante el infrascrito Prefecto,

\section{decretó:}

Permanecer en lo decidido.

$\mathrm{Y}$ notifíquese a todos los interesados, a todos los efectos jurídicos.

Dado en Roma, desde la sede del Supremo Tribunal de la Signatura Apostólica, el día 27 de febrero de 2014.

Raymond Leo Card. Burke

Prefecto

+ Frans DaneELs, o. praem.

Arzobispo titular de Bita

Secretario 


\section{Comentario a los decretos 3.1 y 3.2}

El Obispo D removió de su oficio al Vicario judicial que había sido nombrado para un quinquenio, cuando aún no había trascurrido un año. El motivo del decreto fue que había realizado gastos excesivos en viajes, algo que quedaba fuera de las tareas de su oficio, además con cargo a la diócesis.

El Vicario judicial interpuso ante el Obispo, según dice la Signatura un «recurso» o remonstratio ante el Obispo que decretó la remoción. Como señala Miras, más que un recurso, en realidad se trata de una petición previa al recurso jerárquico, prevista en el c. 1734, $\$ 1$ del CIC de 1983: «Antes de interponer recurso, el interesado debe solicitar a su autor por escrito la revocación o enmienda del decreto». No existe todavía una relación «contenciosa» entre la autoridad y el solicitante; únicamente se pide la enmienda o la revocación del acto, sin necesidad de alegar, si no se desea, los motivos por los que se propone recurrir. Es un paso previo, por el que la autoridad advierte que su acto va a ser recurrido ante el Superior jerárquico ${ }^{34}$ por lo que tiene la oportunidad de revisar la legitimidad de decreto.

Como afirma el c. 1422, el Vicario judicial se nombra para un tiempo determinado, quedando en pie lo que prescribe el c. $1420, \$ 5$, y no puede ser removido si no es por causa legítima y grave. En el caso de los Decretos que comentamos, el Obispo denegó la petición o el recurso que interpuso el interesado.

Ante la denegación de esta «remonstratio», el Vicario Judicial removido presentó un recurso jerárquico ante la Signatura apostólica. Se trata de la impugnación legítima de un acto administrativo singular ante el superior jerárquico de la autoridad que lo emitió. Es un recurso administrativo interpuesto en vía administrativa ante la autoridad ejecutiva competente, que debe resolverlo mediante otro acto administrativo (un decreto singular). Se deduce del texto del decreto que se está comentando, que el recurrente alegó que la sanción se había decidido por una causa ajena al ámbito propio del oficio para el que había sido nombrado. Es decir, que el haber realizado gastos excesivos con cargo a la diócesis, era algo que quedaba fuera de sus tareas como Vicario judicial. Por tanto, no procedía a su juicio, tal sanción disciplinar, cuando sus acciones ilícitas no guardaban conexión con el oficio del que fue privado.

La autoridad dotada de poder ejecutivo, tiene una gran margen de discrecionalidad para considerar la oportunidad de la sanción. La doctrina ha sosteni-

\footnotetext{
${ }^{34}$ J. Miras, voz «Recurso de reposición», en J. OTADUY - A. VIANa - J. SEDano (eds.), Diccionario General de Derecho canónico, III, Thomson Reuters Aranzadi, Cizur Menor (Navarra) 2013.
} 
do que una correcta articulación entre sanciones penales y sanciones administrativas en la Iglesia, favorecería el papel de extrema ratio del derecho penal. En este caso, al no especificarse el monto de las cantidades gastadas, resulta difícil valorar la proporcionalidad de la sanción administrativa, o también si de alguna forma los actos ilícitos podrían ser considerados como penalmente imputables.

En cualquier caso, el Tribunal de la Signatura, basándose en el c. 1420, \$4, considera que cabe destacar que sí existe una relación directa entre un modo de vida inapropiado con el desempeño de un cargo eclesiástico, ya que para ser Vicario judicial se exige ser sacerdote de buena fama, además de doctor o al menos licenciado en Derecho canónico y con no menos de treinta años edad. Por tanto, se consideró que la pérdida de la buena fama, era una causa justa, grave y suficiente para ser removido del oficio. La Signatura apostólica, en consecuencia, rechazó el recurso jerárquico y mantuvo el decreto de remoción.

El art. 114, 2 de la Lex propria de la Signatura Apostólica establece que «el recurrente puede pedir la enmienda o revocación del decreto del Prefecto, aportando las razones, dentro de los diez días desde su recepción». Así hizo el Vicario Judicial, alegando que no se había respetado su derecho de defensa; no había podido acceder a las actas de los diversos «recursos».

El Tribunal alegó que el examen de las actas antes del decreto de remoción y de la remonstratio e incluso durante el recurso jerárquico, no se requiere de acuerdo con el derecho vigente citando, los cc. 50-51 y 193, \$4. En realidad, el c. 50 también dice que «antes de dar un decreto singular, recabe la autoridad las informaciones y pruebas necesarias, y en la medida de lo posible, oiga a aquellos cuyos derechos puedan resultar lesionados». Además, parece que el Tribunal equipara erróneamente en su decisión que el recurrente conociera los motivos por los que fue removido, con el que se hubiera respetado el derecho a la defensa. $\mathrm{Si}$ «en la medida de lo posible» se recomienda oír a los interesados, no es lógico alegar que la ley no obliga a facilitar el examen de las actas, alegando además que el recurrente conocía bien los motivos de su remoción.

Por otra parte, se afirma en el segundo decreto que «la pérdida de la integra fama basta para la remoción, y no se requiere que haya surgido por el propio ejercicio del cargo de Vicario judicial, ni que realmente se baya divulga$d 0 »$. Y se añade que «aquel a quien se le da establemente el oficio de juzgar como Vicario del Obispo, debe ser inmune de toda sospecha de falta de integri$d a d \gg$. Hubiera sido preferible que en lugar de hacer referencia a un juicio de valor como es la «sospecha», se hubiera basado la argumentación en parámetros más objetivos. 


\section{UNA VISITA CANÓNICA A UN TRIBUNAL INTERDIOCESANO ORDENADA POR EL TRIBUNAL DE LA SIGNATURA APOSTÓLICA (DECRETO 43162/09 VT)}

Prot. N. 43162/09 VT

Falsarum notificationum decretae nullitatis matrimonii

\section{DECRETUM}

Visitationem canonicam in Tribunal Interdioecesanum B, ab H.S.T. decreto die 10 octobris 2009 impositam, Exc.mus Moderator eiusdem Fori per Exc.mum Archiepiscopum emeritum B atque per Rev.dum D.num $\mathrm{V}$ mense Novembri 2009 peregit, cuius conclusiones die 7 decembris 2009 ad hanc Signaturam Apostolicam ipse transmittere curavit.

Ex investigatione peracta constat:

- Tribunal Interdioecesanum B quinquaginta quattuor decisiones pro nullitate matrimonii ultimis temporibus ad forum appellationis seu ad Tribunal Interdioecesanum A haud transmisisse et insuper de earundem decisionum confirmatione innuisse;

- Rev.mum Vicarium iudicialem atque Cl.mum notarium Tribunalis Interdioecesani $\mathrm{B}$, ad rem interrogatos, hanc recentiorem praxim his rationibus explanavisse: (a) «Houve erradamente confiança exagerada na esperada homologação da sentença proferida na primeira instancia»; (b) «nem sempre as partes estavam em situação econômica para saldar o debito do Tribunal de Apelação»; (c) «inspirar-se no cânon 1752».

Quibus praehabitis:

\section{SUPREMUM SIGNATURAE APOSTOLICAE TRIBUNAL}

Cum in aperto sit hos gravissimos abusus patratos esse a Rev.mo Vicario
Prot. N. 43162/09 VT

De las falsas notificaciones de declaraciones de nulidad del matrimonio

\section{DECRETO}

El Moderador del mismo Tribunal, a través del Arzobispo emérito $\mathrm{B}$ y el Rdo. Sr. V realizó, en el mes de noviembre de 2009, la visita canónica al Tribunal Interdiocesano B, ordenada por el decreto de este supremo Tribunal el 10 de octubre de 2009 e hizo llegar sus conclusiones a la Signatura Apostólica el 7 de diciembre de 2009.

De la investigación realizada consta:

- Que el Tribunal Interdiocesano $\mathrm{B}$, recientemente, no ha trasladado al Tribunal de apelación, o sea al Interdiocesano A, cincuenta y cuatro decisiones pro nullitate matrimonii. Es más, ha dado a entender la confirmación de las mismas;

- Que el Rmo. Vicario Judicial y el notario del Tribunal Interdiocesano B, al ser interrogados sobre este particular, explicaron esta reciente praxis con las siguientes razones: (a): «Por error, ha habido una confianza exagerada en la esperada homologación de la sentencia dictada en la primera instancia»; (b) «no siempre las partes estaban en situación económica para saldar el cargo del Tribunal de Apelación»; (c) «la aplicación del canon 1752».

Con estos hechos:

\section{EL SUPREMO TRIBUNAL DE LA SIGNATURA APOSTÓLICA}

Conociendo que estos gravísimos abusos han sido cometidos por el Rmo. 
iudiciali, D.no nempe $Y$, annos aetatis suae octoginta septem agente, necnon a Cl.mo notario, Diacono scilicet D.no L, titulo academico canonico experti;

Praetermissis saltem pro nunc quaestionibus de delictis forte in casu patratis necnon de damnis ab iisdem forte illatis;

Considerato quod partes, quae falsas decretae nullitatis attestationes obtinuerunt atque novas nuptias inierunt, in bona fide reliquendae sunt;

Vi art. 124, n. 1 Const. Apost. Pastor bonus atque artt. $35, \mathrm{n} .1$ et $113, \$ 1 \mathrm{Le}$ gis propriae H.S.T.;

Re sedulo examini subiecta in Congressu coram infrascripto Praefecto die 20 ianuarii 2010 habito,

\section{decrevit:}

Rev.mum D.num Y, Vicarium iudicialem Tribunalis Interdioecesani B, amovendum esse et amoveri ab officio;

Cl.mum D.num L, notarium Tribunalis Interdioecesani B, amovendum esse atque amoveri ab officio necnon a quacumque praesentia penes idem Forum;

Exc.mo Moderatori Tribunalis Interdioecesani B praecipiendum esse et praecipi ut relate ad illas quinquagintaquattuor decisiones pro nullitate, de quibus supra, pro unoquoque coniuge in baptizatorum libris haec notatio inscribatur: «Reservatum. Antequam attestatio baptismatis pro statu libero comprobando edatur, Ordinarius loci audiendus est».

Exc.mo Moderatori Tribunalis Interdioecesani B huius decreti exsecutionem committendam esse atque committi, de qua ipse intra sex menses hanc Signaturam Apostolicam certiorem faciat.

Et notificetur Exc.mo Archiepiscopo Moderatori Tribunalis Interdioece-
Vicario Judicial, a saber, el sr. Y, de ochenta y siete años, así como del notario, a saber, el Diácono sr. L que carece de título académico canónico;

Dejando aparte, por el momento, las cuestiones sobre los delitos quizá cometidos en el caso, así como los daños quizá por ellos causados;

Considerando que las partes, que recibieron las falsas notificaciones de la declaración de nulidad y que contrajeron nuevas nupcias, han de ser dejadas en la buena fe;

En virtud del art. 124, n. 1 de la Const. Apost. Pastor bonus, y de los arts. 35, n. 1 y $113, \$ 1$ de la Ley propria de este supremo Tribunal;

Sometida la causa al cuidadoso examen en el Congreso tenido ante el infrascrito Prefecto el día 20 de enero,

decretó:

Que el Rmo. Sr. Y, Vicario judicial del Tribunal Interdiocesano B, debe ser removido, y es removido, de su oficio;

Que el sr. L, notario del Tribunal Interdiocesano $\mathrm{B}$, debe ser removido, $\mathrm{y}$ es removido, del oficio y de cualquier intervención ante el mismo Tribunal;

Ordénese al Moderador del Tribunal Interdiocesano B, a que en relación a las cincuenta y cuatro decisiones pro nullitate, de las que se ha tratado arriba, para cada uno de los cónyuges, en los libros de bautismo, inscriba la siguiente nota: «Reservado. Antes de dar la certificación del bautismo para comprobar el estado de libertad, se ha de oír al Ordinario del lugar».

Encárguese la ejecución de este decreto al Moderador del Tribunal Interdiocesano B, de la cual el mismo en el plazo de seis meses notifique a esta Signatura Apostólica.

Y notifíquese al Arzobispo Moderador del Tribunal Interdiocesano B y a 
sani B atque Exc.mis Episcopis $\mathrm{P}, \mathrm{F}$ et T; Exc.mo Archiepiscopo Moderatori Tribunalis Interdioecesani A; Exc.mo Archiepiscopo M.

Datum Romae, e Sede Supremi Signaturae Apostolicae Tribunalis, die 20 ianuarii 2010.

+ Raimundus Leo BURKE
Praefectus
+ Franciscus DANEELS, o. praem.
Secretarius

los Obispos P, F, y T; al Arzobispo Moderador del Tribunal Interdiocesano A, el Arzobispo M.

Dado en Roma, desde la sede del Supremo Tribunal de la Signatura Apostólica, el 20 de enero de 2010.

+ Raymond Leo BURKE
Prefecto
+ Frans DANEELS, o. praem.
Secretario

\section{Comentario al Decreto 4}

El Tribunal de la Signatura Apostólica ordena por decreto que se realice una visita canónica al Tribunal Interdiocesano B. La Lex propria del Tribunal de la Signatura no trata específicamente de esta vía para ejercer la vigilancia sobre la administración de justicia. No obstante, tal y como está dispuesto en el c. 305 para las asociaciones de fieles, se entiende que a través de la visita canónica lo que se busca es asegurar que en los tribunales no se introduzcan abusos en la disciplina eclesiástica.

De las averiguaciones realizadas en 2009 resultó que se había omitido el traslado de cincuenta y cuatro decisiones pro nullitate y que se había notificado falsamente a las partes el decreto de confirmación. La legislación canónica aplicable en el momento de los hechos, anteriores a 2015, como es bien sabido exigía que la sentencia que declarara por vez primera la nulidad de un matrimonio, junto con las apelaciones, si las había, y las demás actas del proceso, debía transmitirse de oficio al tribunal de apelación dentro del plazo de veinte días a partir de la publicación de la sentencia (c. 1682, $§ 1$ ). Si la sentencia en favor de la nulidad se había dictado en primera instancia, el tribunal de apelación, vistas las observaciones del defensor del vínculo y, si las había, también las de las partes, debía, mediante decreto, o confirmar la decisión sin demora o admitir la causa para que fuera examinada con trámite ordinario en la nueva instancia (c. $1682, \$ 2)$. Sólo cuando la sentencia que por vez primera declaró la nulidad de un matrimonio había sido confirmada en grado de apelación mediante decreto o nueva sentencia, aquellos cuyo matrimonio había sido declarado nulo podían contraer nuevas nupcias a partir del momento en el que se les ha notificado el decreto o la nueva sentencia, a no ser que se prohibiera por un veto in- 
cluido en la sentencia o decreto (c. $1684, \$ 1$ ). Una vez la sentencia se hubiera hecho ejecutiva, el Vicario judicial la notificaba al Ordinario del lugar en donde se celebró el matrimonio. La nulidad debía anotarse en el libro de matrimonios y en el de bautismos (c. 1685) ${ }^{35}$.

Pues bien, el Vicario judicial alegó que había procedido de esta forma, omitiendo el traslado de las causas al Tribunal Interdiocesano A, por la confianza en que las sentencias serían confirmadas, para evitar un mayor gravamen económico a las partes y en atención a la salus animarum (c. 1752).

En el decreto se hace una referencia a la posible responsabilidad penal en la que podrían haber incurrido tanto el Vicario Judicial como el notario, así como a los posibles daños causados. Efectivamente, a mi juicio, los hechos reúnen los elementos típicos de varios delitos recogidos en el Libro VI del CIC. Así el c. 1389, 1 establece que quien abuse de la potestad eclesiástica o del cargo debe ser castigado de acuerdo con la gravedad del acto u omisión, sin excluir la privación del oficio, a no ser que ya exista una pena establecida por ley o precepto contra ese abuso. El c. 1391 establece que podrá ser castigado con una pena justa, según la gravedad del delito, quien falsifique un documento público eclesiástico, altere, destruya u oculte uno verdadero, o utilice uno falso o alterado o quien afirme algo falso en un documento público eclesiástico. Por otra parte, el c. 1437 recuerda que las actas redactadas por un notario hacen fe pública.

En cualquier caso, el Decreto de la Signatura califica los hechos como «gravísimos abusos». De ahí que la sanción que impone es la remoción del oficio tanto del Vicario Judicial como del notario (cfr. c. 193). Una vez más, la Signatura Apostólica reacciona ante los hechos con firmeza, siguiendo la previsión del art. 35 de la LP, contra los ministros de los tribunales, y no sólo contra los abogados o los procuradores, como se había contemplado en la legislación hasta entonces.

Cinco años después, en 2015 el Motu Proprio Mitis Iudex Dominus Iesus suprimió la exigencia del doble pronunciamiento afirmativo conforme ${ }^{36}$.

35 Además el c. 1123 establece que cuando se convalida un matrimonio para el fuero externo, o es declarado nulo, o se disuelve legítimamente por una causa distinta de la muerte, debe comunicarse esta circunstancia al párroco del lugar donde se celebró el matrimonio, para que se haga como está mandado la anotación en los registros de matrimonio y de bautismo.

${ }^{36}$ Este requisito había sido establecido por Benedicto XIV en la Constitución Dei Miseratione, de 3 de noviembre de 1741. Creó la figura del Defensor del Vínculo y estableció que tenía la obligación de apelar toda sentencia que en primera instancia declarara la nulidad de las nupcias; con- 
Como se decía en el texto había un especial interés en dar normas con las que se favoreciera «no la nulidad de los matrimonios, sino la celeridad y una justa simplicidad de los procesos, a fin de que el corazón de los fieles que esperan la declaración de su estado no se vea prolongadamente oprimido por las tinieblas de la duda, a causa del retardo en la resolución del juicio».

En cualquier caso, aunque la legislación haya cambiado finalmente en un periodo relativamente breve de tiempo, los hechos que fundamentaron este Decreto merecían una sanción no sólo por lo que se refiere a la lesión de la fe pública, sino también en cuanto que supone una dejación de la diligencia exigida a quien administra la justicia que según el c. 1454 ha de prestar juramento previamente de que cumplirá recta y fielmente su tarea.

La Signatura Apostólica decide que se deje «en la buena fe» a todos los cónyuges relacionados con las causas que falsamente creían que su sentencia de nulidad había sido confirmada.

¿Qué naturaleza jurídica tiene esta decisión? No se trata de un caso de suplencia ya que, en caso de la celebración de las segundas nupcias por parte de estos contrayentes, el problema no sería la falta de facultad para asistir al matrimonio sino de que tenor del c. 1684, 2 no pueden contraer nuevas nupcias $^{37}$. En 1992, el Tribunal de la Signatura dio una respuesta negativa en re-

dicionó así la firmeza y operatividad de la declaración de nulidad a que hubiera al menos dos sentencias afirmativas (en determinadas hipótesis, podían ser necesarias más de dos) plenamente conformes. Esta disciplina, en lo básico, se mantuvo en el CIC de 1917. En el CIC de 1983 se eliminó la anterior obligación incondicionada que se imponía al Defensor del Vínculo de apelar la primera sentencia que declarara la nulidad del matrimonio pero seguía siendo necesario con carácter general un doble pronunciamiento afirmativo conforme por lo que continuó la exigencia de que tras la primera sentencia afirmativa hubiera un segundo trámite de confirmación, aunque fuera en una modalidad abreviada. El hoy derogado c. 1682 del CIC de 1983 pretendía equilibrar la celeridad con exigencias de certeza. A partir del Sínodo de los Obispos de 2014 se comenzó a considerar si era verdaderamente necesaria la «doble conformidad». Actualmente, tras la reforma operada por el Motu Proprio Mitis Iudex, las causas de nulidad matrimonial se rigen por el mismo principio procesal que rige para el resto de los procesos canónicos: la sentencia adquiere ejecutividad si no es apelada.

37 Según la normativa del canon $144, \$ 1$, la suplencia se puede aplicar al ejercicio de la potestad ejecutiva de régimen, ordinaria o delegada, tanto para el fuero externo como para el interno. De este modo se excluye de la suplencia la potestad legislativa y judicial. El canon indica también dos supuestos concretos en los que actúa la suplencia: error común y duda positiva y probable. El canon 144, $\$ 2$ extiende la posibilidad de la suplencia a las facultades que no tienen carácter estrictamente jurisdiccional. Así pues, se afirma que la suplencia se refiere también a la facultad para confirmar (cc. 882 y 883), confesar (c. 966) y asistir al matrimonio (c. 1111, \$1). Cfr. A. NITA, La suplencia de la facultad de asistir al matrimonio en caso de error común, a la luz de la jurisprudencia de la Rota Romana, Ius Canonicum 78 (1999) 661-708. 
lación con la posibilidad de contraer cuando sólo se contaba con la sentencia afirmativa de primera instancia ${ }^{38}$.

A mi juicio, se trata de un supuesto de dissimulatio canonica por parte de la autoridad. El efecto principal de la disimulación es que la autoridad se abstiene ante un acto, para evitar un mal mayor. Éste permanece ilícito o inválido; la disimulación por tanto es una situación provisional. Si la causa por la cual la autoridad decidió disimular cesa, entonces la disimulación puede cesar, ya que no se adquiere derecho alguno mediante la disimulación. Es lógico, por tanto, que la disimulación suela permanecer en secreto, y la autoridad se contenta con no urgir a la aplicación de la ley en este número limitado de casos.

Por todo lo dicho, es lógico que se ordene la anotación «reservada» en el libro de bautismos, de forma que quede constancia de este acto negativo, de pasividad de la autoridad, en atención a la buena fe de las personas cuya situación es objeto de la disimulación ${ }^{39}$.

${ }^{38}$ Respuesta in casu particulari de 1-II-1990, AAS 84 (1992) 549-550. Puede consultarse en la página web del Vaticano, en: http://www.vatican.va/archive/aas/documents/AAS-84-1992-ocr.pdf.

39 M. Roca, El concepto de tolerancia en el Derecho canónico, Ius Canonicum 82 (2001) 455-473. 


\section{Bibliografía}

Baura, E., Art. 113 della Legge propria della Segnatura Apostolica, en M. DEL PozZo - J. Llobell - J. MiÑAmbres (a cura di), Norme procedurali canoniche, Roma 2013, 124-125.

BERLINGÒ, S., La competenza di legittimità e di merito della Segnatura Apostolica secondo la Lex propria, Stato, Chiese e pluralismo confessionale. Rivista telematica (www.statoechiese.it) (2009).

Bertolino, R., La tutela dei diritti nella comunitá ecclesiali, Ius Canonicum 46 (1983) 547-577.

Canosa, J., La funzione della giurisprudenza della Segnatura Apostolica nello sviluppo del diritto amministrativo canonico, Ius Ecclessiae 17 (2005) 385-416.

—, Il procedimento amministrativo disciplinare previsto in alcuni regolamenti vigenti nella Curia Romana, en D. CiTo (cur.), Processo penale e tutela dei diritti nell'ordinamento canonico, Milano 2005, 433-448.

DaneEls, F., La nuova Lex propria del Supremo Tribunale della Segnatura Apostolica, L'Osservatore Romano, 24-XII-2008, 7.

De Diego Lora, C., Vigilancia y control de legalidad de los Tribunales Eclesiásticos por el Tribunal Supremo de la Signatura Apostólica, Ius Canonicum 59 (1990) 133-149.

De Paolis, V. - Cito, D., Le sanzioni nella Chiesa. Commento al Codice di diritto canonico, Vol. VI, Città del Vaticano 2000.

GÓMEZ ARCE, D. M., Normas de los tribunales eclesiásticos españoles: aspectos económicos, Revista española de Derecho canónico 62 (2005) 501-585.

LabandeIRA, E., Tratado de derecho administrativo canónico, Pamplona 1993.

Llobell, J., La nuova «Lex propria» della Segnatura Apostolica e i principi del processo canonico, Ius Ecclesiae 21 (2010) 441-478.

—, El valor jurídico de la instr. «Dignitas connubii», en R. RODRÍGUEZ-OCAÑA J. Sedano (eds.), Procesos de nulidad matrimonial. La Instrucción «Dignitas connubii», Pamplona 2006, 235-301.

López MEDINA, A., La confirmación obligatoria de sentencias declarativas de nulidad matrimonial. Cuestiones debatidas en la Comisión para la reforma del Código de Derecho Canónico [1977-1981], The Person and the Challenges 5 (2015) 181-223.

MARZOA, Á., Sanciones disciplinares y penas canónicas, Ius Canonicum 28 (1988) 181-196. 
Miras, J., Derecho al buen gobierno en la Iglesia. Una glosa a la doctrina constitucional de Favier Hervada desde el Derecho Administrativo, en AA. Vv., Escritos en honor de Favier Hervada, Pamplona 1999, 367-377.

-, voz «Recurso de reposición», en J. Otaduy - A. Viana - J. Sedano (eds.), Diccionario General de Derecho canónico, III, Thomson Reuters Aranzadi, Cizur Menor (Navarra) 2013, 934-935.

Miras, J. - Canosa, J. - Baura, E., Compendio de derecho administrativo canónico, Pamplona 2005.

NITA, A., La suplencia de la facultad de asistir al matrimonio en caso de error común, a la luz de la jurisprudencia de la Rota Romana, Ius Canonicum 78 (1999) 661708.

Ortiz, M. A., Il difensore del vincolo, en Franceschi, H. - Llobell, J. OrTiz, M. A., La nullità del matrimonio: temi processuali e sostantivi in occasione della «Dignitas connubii», Roma 2005, 27-68.

Pérez-Madrid, F., voz «Sanción», en J. Otaduy - A. Viana - J. Sedano (eds.), Diccionario General de Derecho canónico, III, Thomson Reuters Aranzadi, Cizur Menor (Navarra) 2013.

-, Derecho administrativo sancionador en el ordenamiento canónico, Pamplona 1994.

Roca, M., El concepto de tolerancia en el Derecho canónico, Ius Canonicum 82 (2001) 455-473.

RODRÍGUEZ-OCAÑA, R., La demanda judicial canónica, Pamplona 2002.

VALLINI, A., Dalle «Normae speciales» alla «Lex propria»: itinerario di una riforma, en P. A. BonneT - C. Gullo (eds.), La Lex propria del S. T. della Segnatura Apostolica, Città del Vaticano 2010, 57-75.

—, La función pastoral del Supremo Tribunal de la Signatura Apostólica en la vigilancia sobre los tribunales eclesiásticos, Ius Communionis I (2003) 203-220.

Zuanazzi, I., voz «Bien público», en J. Otaduy - A. Viana - J. Sedano (eds.), Diccionario General de Derecho canónico, III, Thomson Reuters Aranzadi, Cizur Menor (Navarra) 2013, 738-735. 


\section{NUEVAS VOCES DEL DGDC*}

* La sección "Nuevas voces del DGDC" se presenta como el cauce natural de comunicación entre dos iniciativas científicas del Instituto Martín de Azpilcueta, la revista Ius Canonicum y el Diccionario General de Derecho Canónico, promovido por el mismo Instituto, publicado en 2012. Se acogerán términos no contenidos en la edición publicada o nuevas versiones de las voces que hayan de ser actualizadas. Los criterios de extensión y estilo son los establecidos en la obra original. La sección pretende facilitar el proceso de actualización del Diccionario General, que podrá incorporar los textos publicados en la Revista en las sucesivas ediciones. 
